\title{
Sustainable brownfields land use change modeling using GIS-based weights-of-evidence approach
}

\begin{abstract}
Rapid and unorganized urban growth brings about urban sprawl, which leads to the increase in the number of abandoned lands and brownfields within the cities. Revitalization and redevelopment of these areas is one of the key factors of compact urban development to achieve urban sustainability. However, not much research work has been done on the redevelopment of brownfield on the base of compact urban development paradigm in the recent literature. Most researches on this field have mainly considered a single brownfield site for redevelopment on the bases of local neighborhood demand and characteristics. The current paper proposes a brownfields land use change modeling process according to a compact city paradigm in a larger scale perspectives rather than local aspects. The proposed model is a statistical-based weights-of-evidence (WoE) approach in the GIS environment. The growth of three main land use types in Kajang city, Malaysia was predicted using several compact development parameters and other urban and physical site characteristics. Maps that have been created with this process were validated by actual growth maps of these land use types using an area under curve (AUC) technique. The AUC of residential, commercial and industrial land use were gained as 77.4, 78, and $67 \%$, respectively. Finally, these maps were aggregated with an existing brownfields map in order to project future land use types according to planning strategies, as well as compact development characteristics. Results indicate that according to potential and suitability of the site and neighborhood properties, each brownfield can serve the community as single or mixture of several land use types. It is concluded that the combination of land use change modeling techniques and compact urban development theory in GIS environment can provide a strong tool for brownfields redevelopment planning and strategies.
\end{abstract}

Keyword: Brownfield redevelopment; Compact urban development; Geographic information system (GIS); Land use change modeling; Weights-of-evidence 